\title{
Application of Spatial Auto-Regressive Model for Determining Urban Land Market
}

\author{
Md. Shohel Reza Amin*
}

\begin{abstract}
Rapid conversion of agricultural, flood flow and sub-flood flow lands into urban uses at the periphery of Dhaka city increases the demand for developing useful supply, demand, and pricing models. Nevertheless, pricing land offers a challenging task. During high economic growth time, the conventional belief was that land values should soar with increasing demand and decreasing vacancies. Conversely, accurate anticipation of these values is problematic since spatial factors are often influential ones along with other characteristics of land. Moreover, land represents not only a bundle of physical characteristics but also sets of location-specific, transport, urban amenity, socio-economic and environmental characteristics. The extent of such characteristics on land market can be estimated by applying Spatial Autoregression model. The objective of this paper is to carry out an empirical analysis to examine the effects of different land characteristics on land prices in Savar municipality by using Spatial Auto-Regression (SAR) model. In particular, spatial econometric procedures (spatial autocorrelation) and spatial auto-regression analysis are applied to determine spatial dependence among the land value of plots and to evaluate the impact of land characteristics on land prices in the land market of Savar municipality respectively. The findings of this paper reveal that transport attributes have most significiant relationship with the land value and other explanatory variables like municipal amenities, physical characteristics of the plot, employment attraction, and commercial services are also influential factors of land price.
\end{abstract}

\section{Introduction}

Urban land market as a whole is not an organized market but a comprehensive of uncountable businesses involving heterogeneous plots or constructions. In urban land market, a series of imperfections is observed due to the complexity of transactions with the stakeholders and consistent in-equilibrium between demand and supply. In addition, the probability of urbanizing property with sufficient construction of infrastructures and installment of social equipments by the urban government comparing with the demand growth is almost zero. For this reason, the accessibility to urban land market, both planned way and spontaneously, will tend to be increased (Negrão et al., 2004). It is therefore indispensable to develop mechanisms to allow urban government to anticipate what will ensue in land market in the imminent years. Nevertheless, the construction of mechanisms for anticipating the land value is complicated due to the significance of various spatial, temporal and socio-economic attributes of the land value.

The objectives of this paper are to determine the spatial factors influencing land price and to estimate the extent of influence of these locational factors on land price by applying spatial autoregressive model.

Study Area: The research has been based on the case study of Savar municipality. Savar municipality is experiencing a rapid growth of population, urban expansion and a change in traditional agricultural and flood flow land use during the past nineteen years due to the influence of urbanization process of the Dhaka Metropolitan Area (DMA). This gives rise to various problems. One of them is unperceiving growth of land price. The average land price growth rate of Savar municipality during $1985-1995$ was 928 percent, which was 225 percent during the period of 1995-2005. The amazing growth of land price during the period of 1985-95 was because of the declaration of Savar urban area as a municipality and construction of urban infrastructures.

Assistant Professor, Department of Urban and Regional Planning, Jahangirngar University, Savar, Dhaka, Bangladesh, E-mail: shohel_027@yahoo.com 


\section{Research Design}

This study was conducted based on the land price of plots transacted during the year of 2006. In 2006, a total of 971 plots were transacted in Savar municipality. Out of these, 862 transaction data were encoded based on the availability of information on land class, Mouza number, area and price of the plots. Furthermore, lots, which were partially transacted at several times in 2006, were joined together in order to evade any kind of complexity during the spatial analysis. Thus the total number of sample size is 574 and their relevant information were collected from three different sources such as Savar Sub-registration Office, buyers/sellers and local people. From the survey, it exposed that collected information on land price from Savar Sub-registration Office and buyers/sellers were closely related comparing to those accumulated from the local people. Because of the matter of authenticity, the preceding sources are pondered as the pivotal sources.

Aftermath, extensive literature review was conducted for identifying the explanatory variables of land price. Various researches have identified different attributes as the explanatory variables of land price such as distance from the Central Business District (Alonso, 1964; Mills, 1967; and Muth, 1969); proximity to Light-Rail Transit, subways and highways (Haider and Miller, 2000; Al-Mosaind et al., 1995); distance from public goods (Mieszkowski and Mills, 1993; Tiebout, 1956; Hoyt and Rosenthal, 1997; Dubin, 1988; Dubin, 1992; Can, 1990; Can, 1992; McMillen, 1974; and McMillen, 1995); parcel size (Colwell and Sirmans, 1980; Kowalski and Colwell, 1986); buyer and seller characteristics (Chicoine, 1981); environmental characteristics (Garrod and Willis, 1992); landscape indices (Geoghegan et al., 1997); and greenness indices (Sengupta and Osgood, 2003). However, based on the literature review, local knowledge, and expert opinions, the significant explanatory variables of land price under six parameters have been recognized for this study such as size of the property (area), and topographical elevation (contour) under the structural characteristics; population density of the concerned Mouza (pop_den) under the neighborhood attribute; distance from the nearest bus terminal (d_bus_ter), Dhaka-Aricha highway (d_nh), municipality road (d_poura_rd), upazila road (d_up_rd) under the transport attributes; distance from the nearest toxic industry (d_haz_ind) and brick field (d_brickfld) under the environmental characteristics; distance from the nearest market (d_market), post office (d_postoff), police station (d_police), hospital (d_hosp), educational institution (d_edu), municipality facilities (d_muni), dustbin (d_dustbin), and bank (d_bank) under the services and facilities; and distance from the nearest recreational facility (d_recre), religious center (d_relig), employment attraction (d_job) and development organization (d_dev_org) under the socioeconomic characteristics. The locations of these selected variables were identified from field survey and secondary sources.

Later on, the fitness of land price data was tested by pertaining probability distribution function, Chi-square test and percentage distribution in order to determine which method of regression analysis is best fitted to the collected data. Based on the fitness test, land price was regressed against a set of pre-determined explanatory variables by applying the following Hedonic pricing model (Can and Megbolugbe, 1997):

$y_{i}=c+\sum_{j=1}^{n}\left(B_{j} x_{i j}\right)+\mathcal{E}$

Where $y_{i}$ is the price of the $i^{\text {th }}$ plots, $x_{i j}$ is the $j^{\text {th }}$ attribute for the $i^{\text {th }}$ plots, $B_{j}$ is the parameter to be estimated for the $j^{\text {th }}$ attribute, $\mathcal{E}$ is the random error.

The impetus for advocating Spatial Auto Regression (SAR) techniques is premised on the assumption that spatial autocorrelation exists in property data. Spatial autocorrelation describes the relation between the similarity of a considered indicator and spatial proximity. Positive spatial autocorrelation implies a clustering of similar values while negative autocorrelation points to spatial proximity of contrasting values (Anselin and Bera 1998). Moran's I (equation 2) and Geary's $c$ (equation 3) can be calculated to enumerate spatial autocorrelation. 
Moran's $I=\frac{\sum_{i=1}^{n} \sum_{j=1}^{n} w_{i j}\left(y_{i}-\bar{y}\right)\left(y_{j}-\bar{y}\right)}{\left[\sum_{i=1}^{n}\left(y_{i}-\bar{y}\right)^{2}\right]\left(\sum_{i=1}^{n} \sum_{j=1}^{n} w_{i j}\right)}$

Geary's $c=\frac{(n-1) \sum_{i=1}^{n} \sum_{j=1}^{n} w_{i j}\left(y_{i}-y_{j}\right)^{2}}{2\left(\sum_{i=1}^{n} \sum_{j=1}^{n} w_{i j}\right)\left(\sum_{i=1}^{n}\left(y_{i}-\bar{y}\right)\right)^{2}}$

Where $n$ is the number of transacted plots (574); $y_{i}$ is the land value at a particular plot; $y_{j}$ is land value of neighbor plot; $\bar{y}$ is the mean of land price; and $w_{i j}$ is a weight (distance) applied to the comparison between plot $i$ and $j$. Weights are calculated in this study as a simple inverse distance function (equation 4) where the shortest bilateral distance receives a weight of unity and all other distances receive a weight that declines (Blonigen et al., 2006).

$W\left(d_{i j}\right)=\frac{\min _{-} d_{i j}}{d_{i j}} \forall i \neq j$

In case of presence of spatial correlation in the form of substantial spatial dependence, the hedonic price model is expressed as the spatial auto-regression model (Magalhães et al., 2000):

$$
\hat{y}_{i}=c+\rho W y_{i}+\sum_{j=1}^{n}\left(B_{j} x_{i j}\right)+\varepsilon
$$

Where $W y_{i}$ is the spatial lag for land price and $\rho$ is the spatial lag coefficient.

Finally, the ultimate outcome of the Equation 5 was derived by running Classic, Spatial Lag and Spatial Error regression model with the help of GeoDa software.

\section{Ordinary Least Square Hedonic Pricing Model Diagnosis of Ordinary Least Square (OLS) Hedonic Pricing Model}

The descriptive analysis explored that average price of transacted plots in 2006 is TK 66794.28 per decimal and standard deviation is TK 191702.113 per decimal, which revealed extensive divergence of price of the transacted plots. Therefore, a comprehensive evaluation of the outputs of the regression analysis was obligatory. In this regard, the first concern in the model estimation was to identify relative correlation between the dependent variable and the explanatory variables and also among the explanatory variables themselves (multicollinearity). In order to testify at least some relationship (above 0.3 preferably) between dependent variable (land price) and the explanatory variables, the study pigeonholed that not a single coefficient of correlation had accomplished the prerequisite. On the contrary, most of the explanatory variables have strong multicollinearity effect (correlation more than 0.7) among themselves except in the cases of area of the transacted plot, topographical elevation, and distance from dustbin, poura road and DhakaAricha highway. 
Furthermore, the analysis was also weighed up based on the R-square test, which explained that this model embodies only 12.10 percent of the variance in the land price. This was not a satisfactory depiction. Another modus operandi of substantiating the model is "collinearity diagnostics', which also resulted in dissatisfactory delineation.

One of the ways that the outliers, normality, linearity, homoscedasticity and independence of residuals can be verified is by inspecting the residuals scatterplot and the Normal Probability Plot (NPP) of the regression-standardized residuals. From the residual scatterplot and the NPP it is revealed that land price data were highly scattered and deviated from the normality respectively.

\section{Categorization of Plots in Different Groups}

It is obvious that with these blunder outcomes of the multiple analysis of the selected variables, ultimate result could not underscore the pragmatic circumstances of the analogous factors influencing land price of the Savar municipality. This is why, the land price of different transacted plots needs to be stratified. Based on trial and error basis for minimizing the standard deviation of land price, transacted plots were categorized into four groups, such as:

- Group 1 (land price TK 20000- less than TK 30000 per decimal) in which there are 88 plots and the mean and standard deviation of the land price are TK 25272.59 and TK 9846.52 per decimal respectively.

- Group 2 (land price TK 30000- less than TK 40000 per decimal) in which there are 200 plots and the mean and standard deviation of the land price are TK 34697.96 and TK 11425.68 per decimal respectively.

- Group 3 (land price TK 40000 - TK 80000 per decimal) in which there are 156 plots and the mean and standard deviation of the land price are TK 42203.62 and TK 10021.45 per decimal respectively.

- Group 4 (land price TK 88182 - TK 150000 per decimal) in which there are 112 plots and the mean and standard deviation of the land price are TK 120466 and TK 31248 per decimal respectively.

Furthermore, land price distributions of above-mentioned four groups of plots satisfy the basic assumption of residuals scatterplot and the Normal Probability Plot.

\section{Data Fitness Test for Spatial Auto-Regression Analysis}

In order to use the data in the Spatial Autoregression analysis, probability density functions of transacted land price must be specified and a distribution table needs to be created. Data will be better vigorous for linear regression analysis, if they are normally distributed. In the case of abovementioned four groups of plots, land price data were normally distributed with maximum height of the normal probability function curve at the mean of land price. Moreover, the percentile distribution of land price of the four groups revealed that more than 50 percent chance of data would be within the mean level.

Finally, Chi-square test, which describes the magnitude of discrepancy between theory and observation, was conducted in order to determine goodness-of-fit of the data for the analysis.

In case of this study, the null hypothesis was 'the average and standard deviation of the land price data are within TK 25272.59 and TK 9846.52 for group 1; TK 34697.96 and TK 11425.68 for group 2; TK 42203.62 and TK 10021.45 for group 3; TK 120466 and TK 31248 for group 4. The calculated values of Chi-square at 5 percent significance level for group 1, 2, 3 and 4 were 0.876 , $2.263,5.336$ and 0.145 respectively. Nevertheless, the table value of Chi-square at degree of freedom (df) 1 and significance level 5 percent is 3.84 . Therefore, the null hypothesis was accepted for group 1, 2 and 4 data. The contrast was ensued in case of group 3, but it contented the normal distribution and percentile distribution. Therefore, the data of all four groups are en-suited for the spatial regression analysis. 


\section{Category-Wise Derivation of Hedonic Pricing Model}

Satisfying the basic assumptions of correlation, multicollinearity effect, collinearity diagnostics, R-square test, significance level test, residuals scatterplot and the Normal Probability Plot (NPP), the Hedonic Pricing model of group 1, 2, 3 and 4 were derived in equation 6, 7, 8 and 9 respectively.

$$
\begin{aligned}
\mathrm{Y}= & 74950.87+(-2.92) \text { pop_den }+2.58 \text { d_haz_ind }+(-3.84) \text { d_bus_tr }+(-10.72) \text { d_dev_org }+(- \\
& 1.54) \text { d_hosp }+(-9.06) \text { d_dustbin }+(-9.07) \text { d_poura_rd }+(-6.15) \mathrm{d} \_n h \\
\mathrm{Y}= & 61641.80+0.04 \text { area }+0.03 \text { pop_den }+0.64 \text { contour }+0.62 \text { d_brickfld }+(-2.23) \text { d_edu }+9.98 \\
& \text { d_haz_ind }+(-9.86) \text { d_market }+(-21.51) \text { d_job }+(-2.58) \text { d_dustbin }+ \\
& (-18.86) \text { d_poura_rd }+(-0.38) \text { d_nh } \\
\mathrm{Y}= & 273262.05+0.15 \text { area }+(-17.49) \text { pop_den }+275.62 \text { contour }+(-485.96) \text { d_brickfld }+(- \\
& 373.16) \text { d_edu }+52.56 \mathrm{~d} \text { _haz_ind }+39.86 \mathrm{~d} \text { bus_tr }+(-361.96) \text { d_hosp }+(-10.88) \text { d_market }+ \\
& (-284.32) \text { d_job }+(-861.76) \text { d_poura_rd }+(-515.84) \text { d_up_rd }+(-657.58) \mathrm{d} \_n h \\
\mathrm{Y}= & 248901+1.31 \text { area }+8.30 \text { contour }+(-25.35) \text { d_haz_ind }+(-60.55) \text { d_muni }+(-0.08) \text { d_bank }+ \\
& (-90.94) \text { d_hosp }+(32.40) \text { d_job }+(32.10) \text { d_recre }+(-33.37) \text { d_dustbin }+ \\
& (-33.58) \text { d_poura_rd }+(-43.12) \text { d_up_rd }+(7.50) \text { d_nh }
\end{aligned}
$$

Assessing the above equations, it can be said that explanatory variables like population density, distance from the industry, distance from bus terminal, distance from development organizations, distance from hospital, distance from dustbin, distance from poura road and distance from upazila road are significant attributes of land price in case of group 1 plots. Among them distance from dustbin, distance from poura road, distance from the upazila road and distance from the development organization are the most significant ones. On the other hand, other three groups $(2,3$ and 4) have some common significant explanatory variables of land price such as area of the transacted plots, topographical elevation (contour), distance from hazardous industry, distance from employment, distance from poura road and distance from upazila road. Excluding these explanatory variables of land price, group 2 has other attributes like population density, distance form brickfield, distance from school, distance from market, and distance from dustbin. Group 3 has communality with group 2 apropos of the explanatory variables in addition to the previously mentioned variables e.g. population density, distance from brickfield, distance from school, and distance from market. On the contrary, only one variable 'distance from dustbin' is not significant in case of group 2 plots but significant for group 3 plots.

Furthermore, comparison of the explanatory variables of group 4, 2 and 3 reveals that distance from municipal services (street lighting), bank and recreational facilities are significant for the land price of group 4 plots which is totally dissimilar in case of group 1, 2 and 3. While distance from bus terminal is the significant attribute of land price in group 1 and 3, implausibly, distance from dustbin is common for group 1, 2 and 4. In addition, distance from Dhaka-Aricha Highway is common attribute in case of group 3 and 4; and distance from hospital is common attribute in case of group 1, 2 and 4 except group 3.

Eventually, the derived OLS regression equations were promoted to be cross-checked with the average data of the explanatory variables in order to verify whether the equation could look at the precise anticipation of the land price of the plots. The result has deviation of TK 3317.14, TK 7687.33, TK 181.67 and TK 32658.87 from the average land price of group 1, 2, 3 and 4 plots respectively. These deviations may be the consequence of spatial error.

\section{Analytical Test of Spatial Dependence}

Recognition and examination of spatial autocorrelation has a distinct new-fangled paradigm in land economics. Aforementioned to developing Spatial Auto-regression model of the land price, 
data were tested for spatial autocorrelation. In this study, Moran's $I$ was calculated by means of global spatial autocorrelation statistic of GeoDa software (Equation 2).

The Moran's I of the transacted plots in Group 1 exposed that there is a noteworthy positive spatial autocorrelation (0.5646) among the plots. Correspondingly, Moran's $I$ of other three categories of transacted plots defined significant positive spatial autocorrelation such as 0.8376 for Group 2, 0.8416 for Group 3 and 0.6176 for Group 4 respectively.

\section{Fitness Test and Derivation of Spatial Auto-Regression Model}

Prior to spatial regression analysis of land price, it is necessary to provide guidance in identifying the correct model (i.e., spatial lag or spatial error) for deriving spatial auto-regression model after conducting the test of spatial dependence. A spatial lag model is a formal depiction of the equilibrium outcome of social and spatial interaction. Since the observations are for a single point in time, the actual dynamics of the interaction among agents (peer effects, neighborhood effects, spatial externalities) cannot be observed, but the correlation structure that results once the process has reached equilibrium can be modeled (Brock and Durlauf 2001, Durlauf 2004). On the other hand, in spatial error models, the spatial autocorrelation affects the covariance structure of the random disturbance terms. The typical motivation for this is that unmodeled effects spill over across units of observation and hence result in spatially correlated errors.

To test the success of the spatial lag and error model, different criteria need to be evaluated. Ord (1975) gives the Maximum Likelihood methods for estimating the spatial lag and spatial error models. In addition, different social scientists proposed the widening of spatial econometrics to include Bayesian techniques (Bayesian Information Criterion or Schwarz Information Criterion). Given any estimated model, the model with the lower value of BIC or SIC is the one to be preferred because unexplained variation in the dependent variable and the number of explanatory variables increase the value of BIC. The BIC penalizes free parameters more strongly than does the Akaike information criterion (AIC). AIC is a measure of the goodness of fit of an estimated statistical model. It is offering a relative measure of the information lost when a given model is used to describe reality and can be said to describe the tradeoff between bias and variance in model construction, or truly speaking that of exactitude and convolution of the model.

Similarly, the Jarque-Bera (JB) test is a goodness-of-fit measure of departure from normality, based on the sample kurtosis and skewness. The statistic JB has an asymptotic chi-square distribution with two degrees of freedom and can be used to test the null hypothesis that the data are from a normal distribution. Eventually, in order to authenticate the fitness of Spatial Lag and Spatial Error models, five criteria e.g. R-square, Log likelihood, Akaike Information Criterion, Schwarz Criterion and Likelihood Ratio Test was taken into account for comparative evaluation.

In case of transacted plots of Group 1, 19.06 percent, 65.58 percent and 49.57 percent variance of dependent variable was explained by the Classsic, Spatial Lag and Spatial Error models respectively resulting in fitness of Spatial Lag model comparatively. On the other hand, both the value of AIC (1760.03) and BIC (1782.33) indicated the significant acceptance of Classic model because of the fewer explanatory variables and better fitness. Nevertheless, ignoring a spatial lagged dependent variable and spatially correlated errors is the subject of model's biasness, inconsistency and efficiency. This is why, the study can not consider the Classic model. Therefore, comparative evaluation between Spatial Lag and Spatial Error model based on AIC (1881.7 and 1881.35 respectively) and BIC (1906.47 and 1903.65 respectively) indicated better fitness of Spatial Error model. Similarly, Spatial Error model has better fitness comparing to the rest ones based on the Log Likelihood critirion (-931.677, -930.85 and -871.015 for the Spatial Error, Spatial Lag and OLS models respectively) because Log Likelihood will always be negative and will just get larger (more negative) rather than approaching 0 . 
In summary, Spatial Error model was best suited based on the selected criteria. So, the coefficients of the explanatory variables ${ }^{1}$ derived by Spatial Error model were considered for determining the level of influence of the explanatory variables on land value. Similarly based on the above-mentioned criteria Spatial Error model, Spatial Lag model and Spatial Error model were best suited in case of group 2, 3 and 4. Eventually, the Spatial Auto Regressive models for the group 1,2, 3 and 4 were derived in the following equations 10,11, 12 and 13 respectively.

Land price $=43660.2291+(-0.292585)$ spatial lag $+(-0.1491618)$ pop_den $+(-3.289287)$ d_Indus $+(-1.739886)$ d_bus $+(-2.204803)$ d_dev $+(-1.586092)$ d_hos $+(-2.336271)$ d_dustbin + $(-5.069334)$ d_poura_rd + (-2.400886) d_up_rd

Land price $=42231.5+(-0.057921)$ spatial lag $+(0.0979053)$ area $+(0.08741852)$ pop_den + (2.508712) contor + (0.7574042) d_brick + (-7.203303) d_sch + (9.174279) d_indus + (6.3612) d_market $+(-14.84855)$ d_job $+(-4.01954)$ d_dustbin $+(-7.624095)$ d_poura_rd $+(-0.2377236)$ d_up_rd

Land price $=111569.4494+(-0.2731996)$ spatial lag $+(0.01553915)$ area $+(0.147329)$ pop_den $+(0.03476969)$ contor $+(-0.04360441)$ d_brick $+(-10.46348)$ d_Sch $+(0.6305138)$ d_Indus + (-1.138357) d_bus + (-6.548532) d_hosp + (-1.302906) d_market + (8.687336) d_job + (-38.98455) d_poura_rd + (-5.516988) d_up_rd + $(-1.503839)$ d_nh

Land Price $=176645.2295+(0.065050)$ spatial lag $+(1.364536)$ area $+(8.130839)$ contour $+(-$ 26.25236) d_indus + (-56.66778) d_munic + (-3.067364) d_bank + (-84.6925) d_hosp + (30.32396) d_job + (32.27558) d_recre + (-29.7243) d_dustbin + (-31.63951) d_poura_rd $+(-43.81113)$ d_up_rd + (7.347918) d_nh

Later on, these four Spatial Auto-regression equations were promoted to be cross-checked with the average data of the explanatory variables in order to verify whether the equation could look at the precise anticipation of the land price of the plots. The result has deviation of TK 245.9809, TK 200.264, TK 433.9384 and TK 608.4095 from the average land price of group 1, 2, 3 and 4 plots respectively.

\section{Recommendations}

It is assumed that land value is the present value of all future benefits discounted by the sum of the risk free rate and the land's risk premium rate. The risk premium can be indirectly estimated by determining the historical standard deviation of return in excess of the standard deviation of the (risk free asset) market return. Future benefits consist of all estimated future cash flows derived directly or indirectly from the ownership of the asset. This concept is integral to the need to formulate a valuation method, which is based on an estimate of future value adjusted for risk. This future value can only be estimated, however, by analyzing the underlying historical relationships between value and those factors which may influence it. Future benefits can better be understood and estimated through an understanding of the historical relationships. Therefore, the present value of the future benefits of the land needs to be taken into consideration during the spatial economic analysis of urban land market.

Additional study is needed to refute the findings of this study and to identify other buyer and seller characteristics that might influence real estate transactions. Unfortunately, traditional data sets do not include information regarding buyers and sellers. Data sets of buyer and seller characteristics, such as income, family size, occupation of head of household, age of children, etc., should be gathered for subsequent analysis in order to better understand the role of buyer and seller characteristics in land market.

\footnotetext{
Only those explanatory variables were entered which had significant correlation with the dependent variable, significance level was not more than 0.10 , and tolerance level was high (see Equation 7).
} 


\section{Conclusion}

Land is a heterogeneous possession and there are distinctive differences on the characteristics composing the worth of land. It can be said that the spatial auto regressive equations explore the true and vivid scenario of land market in the context of different group of plots. Because we know, urban land market is usually determined by the physical characteristics, socio-economic characteristics and urban services and amenities. From the above discussion, it is revealed that land price equation of Genda mouza justifies the Genda mouza as an urban area and consequently the land price is the highest in this area. On the other hand, land market of the Group 3 plots is strongly determined by the transport accessibility i.e. bus terminals and connective roads. This is why, land price of this category is comparatively higher than Group 1 and 2 plots.

In case of group 1 and 2 plots, actual determining factors of land markets have no significant relationship with the land price. Although some physical characteristics of the plots have relationship with the land price, their correlations are not so significant. In addition, transport accessibility is the main determining factors for these groups. This is because these are the industrial areas and mainly resided by the laborers along with others.

Finally, it can be said that the study outlined strong and significant interaction among land price and transport variables. Nevertheless, other explanatory variables like municipal amenities, physical characteristics of the plot, employment attraction, and commercial services have also significant impact on the land value. Thus, this study needs to be further researched by incorporating temporal data along with spatial data.

\section{References}

Al-Mosaind, M. A., Dueker, K. J. and Strathman, J. G. 1995. 'Light-Rail Transit Stations and Property Values: A Hedonic Price Approach', Transportation Research Record, vol. 1400, pp. 90-94.

Alonso, W. 1964. Location and Land Use: Towards a General Theory of Land Rent. Cambridge: Harvard University Press.

Anselin, L. and Bera, A. K. 1998. Spatial Dependence in Linear Regression Models with an Introduction to Spatial Econometrics, in D. Giles and A. Ullah (eds.) Handbook of Applied Economic Statistics. New York : Marcel Dekker, pp. 237-289.

Blonigen, B. A., Ronald B. D., Glen R. W. and Helen T. N. 2006. 'FDI in Space: Spatial Autoregressive Relationships in Foreign Direct Investment', European Economic Review, October 2006.

Can, A. and Megbolugbe, I. F. 1997. 'Spatial Dependence and House Price Index Construction', Journal of Real Estate Finance and Economics, vol. 14, pp. 203-222.

Can, A. 1992. 'Specification and estimation of hedonic housing price models', Regional Science and Urban Economics, vol. 22(3), pp. 491-508.

Can, A. 1990. 'The measurement of neighborhood dynamics in urban house prices', Economic Geography, vol. 66(3), pp. 254-272.

Cicoine, D. L. 1981. 'Farmland at the Urban Fringe', Land Economics, vol. 57, pp.353-362.

Colwell, P. F., and Sirmans, C. F. 1980. 'Nonlinear Urban Land Prices', Urban Geography, vol. 1, pp. 41-52.

Dubin, R. 1988. 'Estimation of regression coefficients in the presence of spatially autocorrelated error terms', Review of Economics and Statistics, vol. 70(3), pp. 466-474.

Dubin, R. 1992. 'Spatial autocorrelation and neighborhood quality', Regional Science and Urban Economics, vol. 22(3), pp. 433-452.

Garrod, G. and Willis, K. 1992. 'The amenity value of woodland in Great Britain: a comparison of economic estimates', Environmental and Resource Economics, vol. 2(4), pp. 415-434.

Geoghegan, J., Wainger, L., and Bockstael, N. 1997. 'Spatial landscape indices in a hedonic framework: an ecological economics analysis using GIS', Journal of Ecological Economics, vol. 23, pp. 251-264. 
Haider, M. and Miller, E. J. 2000. 'Effects of Transportation Infrastructure and Locational Elements on Residential Real Estate Values: Application of Spatial Autoregressive Techniques', Transportation Research Record, vol. 1722, pp. 1-8.

Hoyt, W. H. and Rosenthal, S. S. 1997. 'Household location and Tiebout: do families sort according to preferences for locational amenities?', Journal of Urban Economics, vol. 42(2), pp. 159-178.

Kowalski, J. G., and Colwell, P. F. 1986. 'Market versus Assessed Values of Industrial Land', AREUEA Journal, vol. 14, pp. 361-73.

Magalhães, A., Hewings, G. J. D. and Azzoni, C. R. 2000. Spatial Dependence and Regional Convergence in Brazil, Discussion paper: REAL 00-T-11, The Regional Economics Application Laboratory, South Matthews, Urbana.

McMillan, M. 1974. 'Open space preservation in developing areas: an alternative policy' Land Economics, vol. 50(4), pp. 410-417.

McMillen, D. P. 1995. 'Selection bias in spatial econometric models' Journal of Regional Science, vol. 35(3), pp. 417-436.

Mieszkowski, P. and Mills, E. S. 1993. The causes of metropolitan suburbanization', The Journal of Economic Perspectives, vol. 7(3), pp. 135-147.

Mills, E. S. 1967. 'An aggregative model of resource allocation in a metropolitan area', American Economic Review, vol. 57(2), pp. 197-210.

Muth, R. 1969. Cities and Housing, Chicago: University of Chicago Press.

Negrão, J., Carvalho, A., Donato, J. and Manhicane, T. 2004. Urban Land Market in Mozambique, Maputo: Research Institute for Development.

Sengupta, S. and Osgood, D.W. 2003. 'The value of remoteness: a hedonic estimation of ranchette prices', Ecological Economics, vol. 44(1), pp. 91-103.

Tiebout, C. M. 1956. 'A pure theory of local expenditure', Journal of Political Economy, vol. 64(5), pp. 416424. 